\section{BAOMS President comments on head and neck cancer crisis}

Commenting on a recent letter ${ }^{1}$ published in the British Dental Journal (BDJ) about the crisis in head and neck cancer surgery and the impact on patient care, British Association of Oral and Maxillofacial Surgeons (BAOMS) President Austen Smith says it is an astute summary of the challenges facing maxillofacial units, adding:

'BAOMS Council member Bhavin Visavadia and colleague Hussein Mohamedbhai raise a very important point that is critical to the immediate future of head and neck cancer surgery provision - based on data from the recent UK CoVidSurg project.

'The CoVidSurg project findings are an example of short-term, rapidly organised and efficiently processed research that offers a timely appreciation of the real-life events affecting acute hospital units across the UK. This sort of fast response research will become even more important in the future - and should serve as a template for similar, rapid extractions of valuable information on trends affecting surgery in the UK.'

\section{Reference}

1. Mohamedbhai H, Visavadia B. P2 Surgery: Crisis... what crisis? Br Dent J 2021; 230: 555 .

\section{FGDP(UK) Fellowship Awards 2020-21}

The Faculty of General Dental Practice UK (FGDP[UK]) has awarded Fellowship to almost 40 individuals in recognition of their professional achievements:

\section{Honorary Fellowship}

Michael Colin Armstrong, Maria D. Clark, Jason Andrew Leitch, Amit Patel, Derek Richards

\section{Diploma of Fellowship of the Faculty of General Dental Practice (UK) \\ By election \\ Hilary Michael Attenborough, Sukhwinder Singh Atthi, Gillian McGregor Lennox, Dominic Brenden O’Hooley, Kulwant Shoker, Robert McNeill Thomson, Chetan Trivedy, Andrew Charles Toy, Brian Westbury, Jason Weng Leong Wong}

\section{By assessment}

Nick Barker, Adrian Bennett, Ntekim Ette, Stephen Robert Burrows, Ruben Garcia, Haidar Hassan, Alexander Holden, Christopher Roberts

Ad eundum [in recognition of an existing Fellowship either of another UK Royal College, or of a recognised overseas body with an award equivalent to that of Fellowship by Assessment of the Faculty]

Ziad Al-Dwairi, Senathirajah Ariyaratnam, Yee Chuen Chan, Stephen Michael Dunne, Robert Dyas, Andrew Howard Eric Eder, Ryan Keir Hughes, Eldo Koshy, David Charles John Langham, Prabhu Manickam Natarajan, Barry Francis Arthur Quinn, Fraser Campbell Sneddon, Gerald Sui, Adrian Thorp, Christopher Jeremy Tredwin, Man Cheong Dennis Wong

The awards have been granted over the last 15 months, and the related post-nominals may be used in perpetuity. These are the final Fellows to be appointed by the Faculty prior to its transfer into the College of General Dentistry, and an opportunity for formal presentation will be arranged in due course.

\section{Diary date}

The British Society of Paediatric Dentistry (BSPD) conference 2021 takes place on 5 and 6 October. It is organised by the Merseyside branch and takes place remotely for the first time. Preceding the conference is the Teachers' Branch Study Day on 4 October.

For more information or to register visit https://bspdconference.org.uk. 